\title{
Theorizing Born Digital Objects: Museums and Contemporary Materialities
}

\author{
Chiara Zuanni
}

\begin{abstract}
:
This paper explores the characteristics of born digital objects and how their materiality is framed and transformed in the musealization process. It draws on vibrant materialism and web archiving, framing born digital objects as assemblages and proposing a distinction between these and reborn digital objects, i.e. their collected counterparts. The paper relates this new framing of digital objects to established museological frameworks, such as analyses of the musealization process through the lenses of semiotics and research on authenticity in relation to digital reproductions, in order to unpick the ontological and epistemological transformation this contemporary form of heritage undergoes in entering the museum.
\end{abstract}

Key words: born digital; contemporary collecting; social media; authenticity; materiality

\section{Introduction}

This paper aims to discuss the materialities of born digital objects and their transformation during the musealization process. Contemporary collecting is increasingly dealing with assemblages of physical and digital objects; however, museum practices for the curation of this material and its understanding are just starting to develop. The paper draws on museum theory, web archiving, and new materialisms to propose a theoretical understanding of these objects, with the purpose of highlighting how a theory-driven framing of born digital collections can contribute to easing and addressing curatorial challenges related to their emergence in the museum.

The paper aims therefore to examine the multiple layers of materiality embedded in contemporary collections and digital curation, discussing the different understandings of born digital objects we employ to frame data in museums and observing the entanglements of agency shaping contemporary collecting practices. It argues that only through a deeper engagement with the materialities of the digital, it will be possible to develop fair, inclusive, and engaging contemporary (digital) curation practices. In particular, the paper will focus on the frame of new materialisms to overcome the dichotomy between physical and digital objects, and highlight instead the entangled nature of digital objects and their relationships with curators and audiences. For the purposes of this paper the discussion will be focused on social media posts, with a focus on their inclusion in social and contemporary history collections. However, given my focus on researching what the musealization process does to this type of material, I suggest that this discussion can also apply to different 'types' of digital objects and museums.

In the first section, I will briefly review the contexts within which born digital objects have been collected. Subsequently, in the second section, I will summarize theoretical approaches to the notion of musealization and introduce the two main perspectives I will be drawing on in this paper, i.e. the distinction between born and reborn digital materials (Brügger 2016) and vibrant materialism (Bennett 2010). The second part of the paper, after briefly acknowledging digitized objects, will focus on born digital and reborn digital objects and their relation to contemporary heritage and museum practices. I will use short vignettes, rather than well-defined 
case-studies to frame this discussion, an approach which I hope will allow me to emphasize the ubiquity, nuanced, and overlapping aspects of such objects, as well as the complex layers that make up their materialities. Throughout the paper, I will therefore draw on the notion of 'reborn digital material' (Brügger 2016) to question the ontological transformation that born digital objects, considered as vibrant assemblages (Bennett 2010), undergo when entering the museum, a transformation affecting their materialities and epistemological understanding, as well as challenging common approaches to 'authenticity' and ethics in the museum field. Ultimately, the paper aims to highlight how theoretical and practical challenges in relation to born digital objects and their constitution as contemporary heritage can productively illuminate each other and shape future digital curation and preservation work.

\section{Collecting (born) digital objects}

Collections of contemporary memories and witnesses of twenty-first century histories and cultures increasingly include born digital objects. The emergence of born digital content and its huge impact in reshaping the ways we experience and create memories (Giaccardi and Plate 2016) has been recognized and researched across different fields and memory institutions. Archives and libraries have been developing solutions for the preservation of born digital documents since the 1990s (Waters and Garrett 1996). The Internet Archive was founded in 1996, while national libraries have also been archiving websites and, more recently, governmental social media streams (Brügger and Schroeder 2017). It is this work by the library and archives community that prompted UNESCO to propose a Charter for Digital Heritage. ${ }^{1}$ Fiona Cameron's recent monograph traces the history of this growing attention to digital heritage and examines the way UNESCO has contributed to its conceptual development through a series of documents, highlighting how these normative instruments 'transferred over from other types of heritage and imposed on digital data as normative forms and praxes' (Cameron 2021: 33).

In the museum field, Nicole Meehan surveyed professionals' definitions of digital museum objects and noticed how different understandings of their materiality and authenticity lead to different framings of these objects and their values (Meehan 2020: 13), encompassing both digitized and born digital objects. Nevertheless, digital objects have been collected across different types of museum organizations. Art museums have been collecting new media art, or digital art, for decades - increasingly facing challenges to its preservation, through emulation or migration, and the preservation of the artist's intended experience of the artwork (Paul 2015, 2017). Design collections have also acquired new digital objects, such as videogames (first collected by MoMA in 2012) and new technologies. ${ }^{2}$ New technologies have been collected also by history and science museums (Foti 2018), while the same objects can also be found in contemporary archaeology work (Garcia Raso 2017; Reinhard 2018; Beale et al. 2019;) and subsequently inform anthropology collections, such as a USB stick found in London and now at the Pitt Rivers Museum in Oxford (Moshenska 2014). Finally, practices for curating social media photographs in museums have been explored (e.g. in the Collecting Social Photography project, see Hartig et al. 2020).

Despite this growing interest in contemporary collecting of born digital objects, compounded also by the emergence of rapid-response collecting practices, there are not yet shared workflows for the curation of these digital objects. The questions they raise are even more urgent after the experiences of 2020: many museums have launched collections related to the COVID-19 pandemic - and due to the situation of lockdown, these collecting initiatives have largely drawn on born digital material (photos and texts submitted via online forms or collected on social media by encouraging the use of specific hashtags). For example, in Austria there have been at least 16 such initiatives led by the GLAM sector, besides a collection of relevant websites launched by the Austrian web archive (based in the National Library) and a few research projects within universities. ${ }^{3}$ The paper will use vignettes relating to these collections: although not drawing on a specific case study, the vignettes represent the experience of many organizations in dealing with the, often ephemeral, ways which people use to record their memories of the pandemic. I argue that the challenges in framing these objects within museum theory affect the understanding of museum practices around 
them: this paper aims therefore to discuss the musealization of born digital objects, in order to highlight their characteristics and contribute to a better understanding of their roles and definitions in museums.

\section{Theorizing (digital) objects}

This section begins by reviewing how 'analogue' objects have been framed within museum studies; it then introduces the work of Jane Bennett, whose vibrant materialism informs the approach to digital objects in this paper. Then, this section briefly examines how museums transform objects, subsequently proposing the division between digitized, born, and reborn digital objects which will scaffold the discussion in the second part of the paper.

Objects in museums have been discussed through a series of different frames, increasingly in the field of material culture (Hicks 2010). For example, their perceptual and ontological values have been discussed in relation to their histories within museums (Byrne 2011; Dudley 2012), their agency on both staff and visitors (e.g. Hill 2012), their uses in sociopolitical constructions (e.g. Janes and Sandell 2019), and their tactile, sensorial, embodied, and emotional impact (e.g. Dudley 2010). In order to unpack the hermeneutical and relational characteristics of objects, material culture studies have drawn on actor-network theory (Hassard and Law 1999; Latour 2005), which extends the concept of agency to non-humans, assigning them a role in shaping the networks they create with human actors. The discussion of the notion of agency by Gell (1998) in relation to artworks, in which agency was retained by humans, but distributed through the objects, was also an early application of such new approaches to agency in art history. Network studies applied to museum collections have demonstrated the variety of stakeholders and knowledge built around these objects (Gosden and Larson 2007) and the notion of 'boundary objects' has emphasized how objects might sit at the intersection of different communities of stakeholders (Star and Griesemer 1989), while object biographies (Kopytoff 1986) have unpacked the multiple meanings and values of an object throughout its life-cycle (Holtorf 2002), and afterwards, in the museum (Alberti 2005). While I would argue that the notion of object biography has a significant, and yet largely untapped, potential in understanding the formation and circulation of digital cultures, here I want to focus first on the notion of agency applied to digital objects. In doing so, I am drawing on the work of Jane Bennett (2010), who proposed the notion of 'thing-power' to define the agential capabilities of non-human actors. She draws on Spinoza's notion of 'affective bodies' with the aim of highlighting how 'bodies enhance their power in or as a heterogeneous assemblage' (Bennett 2010: 23). Her definition of 'assemblage' is derived from Deleuze and Guattari (2013), and she defines assemblages as:

ad hoc groupings of diverse elements, of vibrant material of all sorts. (...) They have uneven topographies, because some of the points at which the various affects and bodies cross paths are more heavily trafficked than others, and so power is not distributed equally across its surface. Assemblages are not governed by any central head: no one materiality or type of material has sufficient competence to determine consistently the trajectory or impact of the group. The effects generated by an assemblage are, rather, emergent properties (...) Each member and proto-member of the assemblage has a certain vital force, but there is also an effectivity proper to the grouping as such: an agency of the assemblage (Bennett 2010: 23-4).

Vibrant materialism argues, therefore, that agency 'becomes distributed across an ontologically heterogeneous field, rather than being a capacity localized in a human body or in a collective produced (only) by human efforts' (Bennett 2010: 23). In this paper, I will apply these ideas to digital materials as they emerge in, or enter, the museum. Bennett's famous example for unpacking the agency of such assemblages was the blackout that affected a large part of the US power grid in 2003, and I will attempt to follow her model, applying it to born digital materials in the context of museums' digital collections.

The musealization process transforms 'things' into 'objects' (Mairesse et al. 2010), or better 'museum objects' ('musealia'): the process of selection, acquisition, and curation assign 
value to a previously unnoticed 'thing', positioning it in front of the visitor as a sign of another world. In this sense, Pomian (1990) has distinguished between the potential of a meaning inherent in objects, semiophores, from the specific configurations this meaning can take in its relationship with the human onlooker, i.e. its semiotic aspect. In the UK, Susan Pearce has drawn on de Saussure and Barthes to explore the semiotic power of objects, concerned by the meanings museums can convey through their collections (Pearce 1994).

In short, objects that enter into a museum not only undergo a formalized process of acquisition, but also a more subtle transformation, which separates them from their everyday (past or present) use and assigns them a different value, in the realm of heritage objects. These discourses apply to objects, which - as Pearce says - are distinguished by the 'materiality of objects and the physicality of their anchorage in time and space' (Pearce 1992: 17). However, a digital object - e.g. a social media photo/post - does not occupy such an evident tangible physical space, and thus the distinction between its 'before' and 'after' life in museums also becomes more intangible. For digital preservation specialists, there would be a clear difference between the digital infrastructures originally hosting our objects, whether webpages or mobile applications, and the archival infrastructure in which memory institutions try to collect them. In this sense, I would argue that it is useful to consider the distinction highlighted by Niels Brügger between 'digitized', 'born digital', and 'reborn digital' objects. In his formulation, physical objects can be recorded in a digital format (whether as images, 3D models, etc.); alternatively, objects can be created directly in a digital space, e.g. websites, thus constituting born digital material. When born digital material is collected in web archives, Brügger speaks of 'reborn digital material', highlighting how the collected web becomes something different from the actual web. I argue that this process from born digital material to reborn digital material is also useful for unpacking the ways museums approach the collection of digital objects; in other words, it is a useful way of framing the transformation from 'things' into 'objects' when dealing with digital materials in museums.

In the following sections, I will consider digital objects as assemblages and the different agencies and semiotic potentials during their lifecycles. As Brügger highlights, the difference between digitized, born, and reborn digital material is a difference in provenance. Although these are broad categories, they offer a first categorization of digital objects, which could then be further broken down according to a variety of criteria (e.g. precise provenance, formats, content, etc.). In the following discussion, I will briefly mention digitized objects, but my focus will then be on born and reborn digital objects, with the aim to reflect on the processes these objects go through when entering the museum, and how their musealization differs from that of analogue objects.

\section{Digitized objects}

Digitized objects are by far the most discussed in cultural heritage, given the longer history of reproducing analogue objects in a digital format. Brügger states that the 'main characteristic of digitized material is that its "becoming digital" is based on an original that was not digital' (Brügger 2016). These objects can therefore consist of digital reproductions (images or 3D models) and/or of digital data describing the objects (metadata). The preservation of such digital information, to maintain a documentation of the object for the future, is an important argument both for digitization in the first place and for digital preservation work in the museum; however, a full discussion of the hermeneutical challenges raised by these objects is beyond the purposes of this article and I will only summarize it briefly.

In the case of computer-based visualizations, the London Charter $(2009)^{4}$ and the Seville Principles $(2011)^{5}$ proposed guidelines in regards to the information these reproductions should be accompanied by. In parallel, a significant part of digital heritage literature has focused on the changes heritage objects undergo in this transformation, exploring issues of authenticity in relation to digital surrogates (Jeffrey 2015; Di Giuseppantonio Di Franco et al. 2018) and their use in dissemination and engagement work. Departing from Benjamin's notion of 'aura', an object's 'presence in time and space, its unique existence at the place where it happens to be' (Benjamin 1969 [1936]), researchers have questioned issues of authenticity in relation to digital reproductions. If Latour and Lowe argued that the 'aura' could migrate 
to a digital copy (Latour and Lowe 2010), more recently the ACCORD project argued that community-produced '3D models also acquire new forms of authenticity' (Jones et al. 2018: 349). The question of authenticity, and its value in relation to digital reproductions, has also been investigated across different cultures (Brown 2007; Geismar 2018).

Furthermore, the description of objects within databases, relying on shared standards (such as CIDOC-CRM), also allows a representation of a record of the object and its associated information. However, as Johanna Drucker noted, data are indeed capta, i.e. 'taken not given, constructed as an interpretation of the phenomenal world, not inherent in it' (Drucker 2011), and there are thus important questions to be asked on the information we select to be represented within semantic models, in particular in relation to the inclusion of non-Western views (Geismar 2018). At the same time, databases can be studied as artefacts per se, as born digital representations of our knowledge systems in relation to heritage.

\section{Born digital objects}

In Brügger's definition, born digital material 'has never existed in any other form than digital' (2016), and it includes both digital media (e.g. DVDs) and internet content. In this section, I will focus on the latter, and in particular on social media content. As discussed in a previous section, social media are now integral to many aspects of our life: memory institutions have been fascinated by the possibility of using them to collect witnesses of contemporary society. Similarly, different research fields have been concerned by social media and have developed methods and frameworks for studying those platforms and the impact they have on society. For example, digital anthropology (Horst and Miller 2012; Geismar 2016) and digital ethnographies (Hine 2000; Kozinets 2010; Murthy 2011; Pink et al. 2016) have examined methods and approaches to the study of relationships between humans and technology as well as online communities; whilst media studies (Manovich 2001, 2009; Lievrouw and Livingstone 2006; Tifentale and Manovich 2015) and media archaeology have contributed to our understanding of the material and social aspects of new media (Huhtamo and Parikka 2011; Parikka 2012). For the purposes of this paper, I will mainly focus on the ontological constitution of social media content as an assemblage, in order to subsequently discuss its transformation in museum objects.

Considering the materiality of a social media post, unpacking it as Bennett did in her example of the electric grid, reveals a complex assemblage. In the following paragraphs, I will use a short everyday vignette to develop a tentative analysis of such networks.

It's Spring 2020. I'm in lockdown, like most of the world. This afternoon, I've gone out for a walk: it's sunny, and there are a few other people following my same path across this park. However, we all keep a distance from each other. I reach a side wall, and there is a new graffiti: it's a nice message of hope through these pandemic times, it must have been painted recently. I take my phone out of my pocket and take a picture of it. I immediately send the image via WhatsApp to a friend; later, I will post it on my Facebook profile and maybe also on Instagram. Maybe I should post the image also on Twitter - would \#CovidArt be the right hashtag for it?

This short text might represent the common experience of many social media users, walking around, taking photos with their phones and sharing them on social media. In addition, the topic of the photo will be, in this case, related to the COVID-19 pandemic. But how did the social media post come to be?

On the one hand, there is the author (myself), the instrument (my smartphone), and the object (the graffiti) that inspired the photograph and its short accompanying text. These, as well as the surrounding context, pose problems known and debated in relation to other types of museum objects, and - to a certain extent - can be described within existing frameworks and processes. In particular, photography collections have long lived in a liminal space between documentation and museum objects (Edwards and Hart 2004; Edwards and Morton 2015; Bärnighausen et al. 2020) and it is not surprising that social media content has been considered an expansion within this type of collection (Hartig et al. 2020). 
On the other hand, my social media post has been shared on complex platforms, through the mobile applications on my smartphone that launched a series of POST calls to the social media APIs (application programming interfaces), which allowed my phone to send data to the respective servers that in turn processed my content and stored it on the relevant database. The network of servers, on which those databases are hosted, include dozens of thousands of servers distributed across the world, each platform with its own data centres. I would therefore argue that a social media platform, due to this infrastructure comprising servers in data centres all around the world, can appropriately be defined as an assemblage of the type described by Bennett. Most of the time, the materiality and environmental costs of such infrastructure remain invisible. As a user, I will most likely notice the existence of this complex network only in case of a major outage, i.e. when a platform is 'down' - so that it is the lack of digital content that will reveal to me the actual materiality of the infrastructure supporting it, and its agency.

Besides, the materiality of these platforms is highlighted in legal, socio-political, and economic discussions. As new materialisms highlighted, "The myth of a "dematerialized" and "weightless" knowledge economy tends to obscure the fact that computers are consuming vast amounts of energy and that many physical commodities need to be transported and sold for this economy to function' (Casemajor 2015: 13). Thus, the physical locations of data centres become important to local economies and job markets, to taxation systems, to legislation regulating the treatment of users' data (for example, in Europe, the General Data Protection Regulation), and to environmental policies. Since economies of digital labour have important tangible effects on both workers (Fuchs 2014) and societies at large, dealing with the materiality of a social media platform means dealing also with a complex range of factors affecting local and global governments and population. If this argument supports the presentation of social media platforms as assemblages similar to those discussed by Bennett, it is important to note that this approach could be applied in a more granular way to the infrastructures' components, down to the AMD or Intel chips at the heart of the servers or the components of the devices we use to interact with those platforms (smartphones, tablets, laptops, etc.).

In the above discussion, I proposed that a social media post can be understood not only as comprising its immediate visual and textual content, but also as part of an assemblage. As a consequence, I would argue that questions of authenticity in relation to the author, the ontological aspects of the content ('has it been altered?'), and its epistemological value ('is it truthful?'), which can be asked of any historical source, are already compounded by questions about the transformation my photo and text undergo during their processing in a social media platform. As Kirschenbaum notes, 'When working with software, we establish and dissolve formal materialities routinely as digital objects move between different information states' (Kirschenbaum 2008: 142). Social media compress and resize images uploaded to their platforms: while this is seen as a necessary tradeoff to guarantee enough bandwidth for the sites to load and deliver content quickly, the quality of the images is often altered. For example, a JPEG photo, taken with my phone, will be compressed and resized when uploading to Facebook. If a friend downloads it, and subsequently shares it again, the quality will reduce further: this progressive, albeit each time imperceptible, degradation of an image affects widely circulated content (to the point that this has become a type of meme in itself, i.e. deep-fried memes, see Kowalchuk 2018). Thus, the authenticity of my photo, once uploaded and shared on a platform, would be questioned from a digital forensic perspective. Similarly, provenance might refer in the first instance to the author of a post, but it can also be traced to the data centre hosting the specific content (thinking about where the content is written on a server, its forensic origin), reflecting the ways the post has travelled through the infrastructure, e.g. from a personal device to a server, and has subsequently been queried by its viewer. The agency of assemblage is therefore critical in delivering content through its material infrastructure. This agency leads to the circulation of information, a global participation in events and cultural trends, and the environmental and economic impacts of the infrastructure.

Furthermore, over time, the experience of social media content might also change since platforms evolve their design and functionalities, affecting the ways we interact with them (Bruns 2008; Burgess et al. 2017; Burgess and Green 2018; Vann et al. 2019). For example, the first interface of Twitter was very different from the current one; the initial limit 
for a post was 140 characters, whereas now it is 280 characters; the idea of using hashtags to 'index' content was proposed in 2007 by Chris Messina (Twitter was launched in March 2006); or, just to cite another recent example, in late 2020 Twitter has introduced 'Fleets', temporary posts, following the trend initiated by other platforms (cf. Facebook and Instagram 'stories'). Thus, Twitter users' experiences and ways of communicating have changed notably - albeit imperceptibly - over the years. From the perspective of a future researcher, even the authenticity of the platform could be questioned: given the ephemerality of a platform experience, capturing snapshots of such experience in different moments could lead us to question whether there is an 'experience of Facebook', or whether we should instead focus on or ask about, e.g., 'the experience of Facebook in 2009' rather than 'in 2019'. This problem is not new to researchers working with web archives, who have also highlighted how the archived web can offer a perspective on the history of the web and its communities (see, for example, Ian Milligan (2017) on Geocities).

In conclusion, born digital material exists 'on the web', embedded in societies, economies, and politics. Social media platforms have established themselves as places to share and curate user-generated content, which is processed in black boxes (i.e. besides the APIs endpoints, users do not have access to a complete documentation of the platform's infrastructure) and hosted in distributed data centres. For these reasons, I argue that social media platforms can be considered as assemblages, made up of multiple parts (e.g. files, servers, databases, code), whose agency is established through the seamless flow of information between these components, and the human actants around them - shaping their content, contexts, and infrastructure. As such, capturing born digital material is a complex task - and I will argue in the next section that approaching them as 'reborn digital objects' in collecting practices eases some of the questions and tensions inherent in this process.

\section{Reborn digital objects}

Brügger (2016) suggests 'reborn-digital material' as a term 'to characterize born-digital material that has been collected and preserved, and that has to a large extent been changed in the process of collecting and preserving'. In doing so, he draws on the example of the archived web, and compares it to digitized material 'since both types are transformations of already existing material, analogue and born-digital, respectively', highlighting how 'the material that is being transformed as well as the processes of transformation are very different, and so are the results' (Brügger 2016).

As in the previous section, I will begin with a vignette, before proceeding to unpack ideas of materiality, authenticity, and provenance as applied to reborn digital objects. This time, I am writing from the perspective of a curator.

It's Spring 2020. My museum is closed and we're all working from home. We've decided that it's important to document memories of the pandemic, so to preserve witnesses of this period for future historians - and it's also a good way of developing a participatory collecting project. We've created a simple form through which people can upload their 'pandemic memory': we're asking them for a photo, a short description, a contact, and to sign a copyright release statement. We're promoting the form through our social media and website; and l've also started to comment on users' photos shared in public groups on Facebook or with relevant hashtags on Instagram and Twitter, asking users whether they would be interested in giving them to the museum and sharing a link to our initiative. I hope this will allow us to document well the range of experiences in this weird year.

The collection of memories and witnesses of the pandemic, as in the vignette above, has prompted a broader interest in digital contemporary collecting projects in 2020 . These projects have collected material through online forms, which included an acknowledgement of the acquisition process, or dedicated hashtags, allowing users the possibility to 'opt in' and thus, again, respecting users' privacy and copyright. In this sense, the process is different from that discussed by Brügger for web archives, in which crawlers are launched to collect material 'in the wild'. However, I suggest that this is still a useful definition, when considering what happens to a born digital object entering a museum collection. 
Although the musealization of an analogue cultural heritage artefact has been variously conceptualized and defined within museum studies (see above), a common denominator is that the object is separated from its previous 'life' and gains a new value as 'museum object', used to convey and represent a set of knowledge and meanings. After this first passage, the object can subsequently be digitized, its information recorded in a database, and its digital reproduction presented online or/and used in a digital engagement project. The collection of a born digital object compresses all these processes in a single passage: there is not a sequence from 'thing' to 'object' and then to 'digitized object'; instead, a 'born digital' object becomes immediately a 'reborn digital object', or - in other words - a 'museum digital object'.

It is impossible to collect the assemblage I described social media content being part of, given the breadth and complexity of platform infrastructures. Analogue objects are also embedded in past or present societies at multiple levels, which become part of their semiotic potential and are revealed in their museum interpretation. However, in these cases, the collected object preserves its materiality, which carries all these potential meanings: it points to the place and economies of its production, to its values and the events it has gone through (exchanges; damages; etc.), and it can be used to signify political, religious, social, artistic, etc. contexts. Conversely, in the case of born digital content, the materiality is significantly transformed when recording a copy of the visual and/or textual content of a social media post in a museum's system.

The born digital object is no longer hosted on a commercial platform infrastructure or on a private user's phone memory card/hard disk, but it is now inscribed in a museum computer and uploaded on its server. A standardization of formats and metadata could become part of the accession process, for example by altering the format of an image. In the following discussion, I will consider the materiality of a social media post, as encoded on its platform, to be substantially lost - and I will consider the implications of this loss for the authenticity of a reborn digital object. I will unpack this question through three facets: form, content, and experience.

The form of the reborn digital object is different from that of the born digital object, itself potentially existing in multiple, often ephemeral, versions (e.g. on tangible supports such as a phone memory or a hard drive, or on web infrastructures, such as social media platforms). The reborn digital object is de facto a copy of the same material as the born digital (i.e. bytes inscribed on a support), but remodelled within a different infrastructure and captured in a specific moment in time. As such, it can only evoke the original assemblage of which the object might once have been part, but it is now completely detached from it. It propagates and evokes the agency of the assemblage, but it does not contribute to shape it further. In short, from a forensic analysis perspective, the materiality is different - and the reborn digital object is not 'the authentic' born digital object. Indeed, this is also a problem that has been faced in the curation and preservation of digital art, where there is a tension between the original media used by the artist and the need of migrating/emulating it in order to guarantee its conservation (Engel and Phillips 2019).

Since the born digital counterpart might continue to live in the assemblage and evolve alongside it, its content is therefore also captured only as a snapshot in time. In regards to the archived web, Brügger (2016) notes that '[it] must be regarded as a unique version - a version of a (probably) lost original, and very likely one version among other versions, none of which can be identified as the original'. I would suggest that for social media content, there can indeed be an 'original', i.e. the first text/visual content posted by a specific user at a given date and on a given platform. Thus authorship and content of a given post could be identified in many cases, and this is crucial for guaranteeing a legal and ethical collection: data protection and copyright legislations demand that we obtain permission from the author, while museums also need this information in order to take appropriate ethical decisions. ${ }^{6}$

The truthfulness of the content is a different matter: while 'fakes' are present throughout history, the broad circulation of so-called 'fake news' across digital media is peculiar to the twenty-first century. As in the case of dubious analogue objects, curatorial choices will inform the interpretation of these objects and the narratives and contexts in which they will be presented to the public. In this sense, reborn digital objects could become representatives of contemporary events, trends, and social life; of language changes and of digital cultures; 
or, as in the previous vignette, documentary evidence of analogue artefacts (e.g. graffiti), i.e. versions of a digitized object (the digital reproduction of the graffiti). In all cases, their interpretation in a museum can rely on multiple possible meanings and narratives.

However, presenting the reborn digital object in a museum also means dealing with how to present the experience of the 'wild' web in a separate network: how can a museum-curated reborn digital object convey the fragmentary, albeit seamless experience of navigating the internet to access, share, and read content? It is impossible to replicate the assemblage of a platform, often linking to the even bigger assemblage of the Web 2.0: reborn digital objects sit within the closed system of a museum. Attempts to reproduce, even if in scale, the digital assemblages they come from would require the possibility of accessing links, services, and webpages in the 'wild', while enabling visitors to interact with these resources and generate content.

This continuum between the reborn digital object in the museum and the continuously evolving digital objects outside of the institution would involve numerous challenges in terms of security and digital preservation (given the constantly evolving nature of the web). First, the linking to external content without a constant moderation might lead to the inclusion in the network, around the object, of problematic content, from both an ethical perspective, e.g. violent, racist, or pornographic content, and also for its preservation, e.g. malwares. An important consideration for museums in curating an experience of such objects is therefore to acknowledge the problematic aspects of the social web and to create a safe environment for their audiences. Second, the reborn digital object would need to be regularly migrated (or, alternatively, the platform would need to be emulated): these processes might further detach reborn digital objects from born digital objects, as they were first experienced in the 'wild', thus affecting their experience and contextualization in the museum.

To conclude, I have suggested that the musealization of a born digital object into a musealia does not only detach the object from its surrounding environment and relationships, thus opening up the possibility of exploring its meaning through a curatorial intervention, but also substantially alters its materiality. Preserving the essence of a born digital object, its materiality defined as the integrity of its code and of the assemblages it belongs to, is impossible, and attempting to do so raises too many risks, i.e. the digital preservation of these networks and the exposure of audiences to problematic links without contextualization. Conversely, accepting that the materiality of a born digital object will change during the musealization process allows museums to focus on developing strategies for the digital preservation of the reborn digital object and, crucially, to explore its semantic values and propose richer narratives of trends and events of the twenty-first century.

\section{Conclusion}

Preserving documents of contemporary digital practices and researching the impact of this digital transformation on society has concerned researchers across different fields over the last 25 years. Due to the increasing use of digital media for creating, sharing, and informing our memories, and the ephemerality of such media, there is an urgency in understanding and developing curatorial practices for born digital objects. In this paper, I have drawn on the work of Jane Bennett and Niels Brügger to explore the characteristics of born digital heritage and the theoretical challenges for its transformation in museum objects. I have briefly acknowledged the questions digitized objects pose in relation to their authenticity, before discussing born digital objects, i.e. content that lives in complex networked assemblages in which agency is distributed and enacted at multiple levels, and whose ephemerality and social construction make it extremely difficult to capture in a memory institution. However, it is clear that such content is increasingly important for the representation of contemporary heritage - and I have defined collections of it as 'reborn digital objects'. I have explored the challenges in the musealization of these objects through the lens of authenticity, in relation to its form, content, and experience. I have noted that an 'analogue' artefact acquires value through the musealization process, and - when digitized - raises questions about the (dis)continuity of its 'aura' in its digital copy. Instead, I have argued that a reborn digital object is collected as a copy of a born digital object in a given time and space. Detached from its position in the 
social networked web, the object might therefore lose part of its original aura. The content, however, might remain the same (e.g. same image, same text), although its truthfulness needs to be ascertained and contextualized - as in many other representations of events present in museum collections. However, the scale at which 'fake news' is disseminated online and the ways this phenomenon shapes contemporary society and debates is unprecedented and poses new challenges at the intersection of museum interpretation and ethics. Finally, I have suggested that it is also impossible to replicate the experience of encountering born digital content on the web, but - again - this is where curation and interpretation intervene in framing the reborn digital object as part of a broader system. In this sense, the reborn digital object - as do many other museum objects - becomes a semiophoros for experiences of the contemporary world. As a catalyst for discussion on the future of the digital society, its problems, and its assemblages, the reborn digital object might therefore not only contribute to strengthening museums as fora, but it might also be assuming its own aura.

This paper presents still many open threads and questions that will need to be further investigated in future research: there is still a lot of research needed in relation to the processes enacted by memory institutions for curating these objects and the possible solutions that can be adopted for such processes. I argue that a deeper understanding of the assemblages in which those objects sit, and their agencies, can contribute to a better understanding of born digital objects and of practices for their musealization. Their transformation when entering the museum, from born to reborn digital objects, enables the setting of boundaries to the scope and breadth of our collections, and a better understanding of the interpretation and ethical practices they require. To conclude, reborn digital collections still pose numerous challenges to museums practices, in relation to their acquisition, curation, preservation, and interpretation - challenges that often require interdisciplinary work on the boundaries of digital preservation, the digital humanities, cultural studies and museum communities. Here, I have proposed a different perspective, looking first at the assemblages of materiality and agency in born digital objects, and then considering their implications in reborn digital objects, suggesting that the musealization process condenses the questions we ask of analogue objects and needs, therefore, to be better understood, so as to fully comprehend the constitution of twenty-first century heritage collections.

Received: 27 February 2021

Finally Accepted: 19 July 2021

\section{Acknowledgements}

I am grateful to the anonymous reviewers for their very helpful suggestions in improving this paper.

\section{References}

Alberti, S. (2005) 'Objects and the Museum', Isis, 96 559-71. https://www.jstor.org/ stable/10.1086/498593

Bärnighausen, J., Caraffa, C., Klamm, S., Schneider, F. and Wodtke, P. (2020) PhotoObjects: On the Materiality of Photographs and Photo Archives in the Humanities and Sciences, Berlin: Max Planck Gesellschaft zur Förderung der Wissenschaften. https://www.mprl-series.mpg.de/media/studies/12/studies12.pdf

Beale, G., Schofield, J., and Austin, J. (2019) 'The Archaeology of the Digital Periphery', Journal of Contemporary Archaeology, 5 (2). https://doi.org/10.1558/jca.33422

Benjamin, Walter (1969 [1936]) 'The Work of Art in the Age of Mechanical Reproduction', in Hannah Arendt (ed) Illuminations, 217-51, New York: Schocken Books.

Bennett, J. (2010) Vibrant Matter: A Political Ecology of Things, Durham, NC: Duke University Press. 
Brown, D. (2007) 'Te Ahu Hiko: Digital Cultural Heritage and Indigenous Objects, People and Environments', in Fiona Cameron and Sarah Kenderdine (eds) Theorizing Digital Cultural Heritage: A Critical Discourse, 77-93, Cambridge, MA and London: The MIT Press.

Brügger, N. (2016) 'Digital Humanities in the 21st Century: Digital Material as a Driving Force', Digital Humanities Quarterly, 10 (2). http://www.digitalhumanities.org/dhq/ vol/10/3/000256/000256.html

Brügger, N. and Schroeder, R. (2017) The Web as History: Using Web Archives to Understand the Past and Present, London: UCL Press. https://doi. org/10.14324/111.9781911307563

Bruns, A. (2008) Blogs, Wikipedia, Second Life, and Beyond: From Production to Produsage (Digital Formations, Vol. 45), New York: Peter Lang.

Burgess, J. and Green, J. (2018) YouTube: Online Video and Participatory Culture, Cambridge: Polity Press.

Burgess, J., Marwick, A. and Poell, T. (eds) (2017) The SAGE Handbook of Social Media, Los Angeles: Sage.

Byrne, S. (2011) Unpacking the Collection: Networks of Material and Social Agency in the Museum, New York: Springer.

Cameron, F. (2021) The Future of Digital Data, Heritage and Curation in a More-thanHuman World, Abingdon and New York: Routledge.

Casemajor, N. (2015). 'Digital Materialisms: Frameworks for Digital Media Studies', Westminster Papers in Culture and Communication, 10 (1) 4-17. https://www. westminsterpapers.org/article/id/206/

Deleuze, G. and Guattari, F. (2013) A Thousand Plateaus: Capitalism and Schizophrenia, London: Bloomsbury Academic.

Di Giuseppantonio Di Franco, P., Galeazzi, F. and Vassallo, V. (2018) 'Introduction', in Paola Di Giuseppantonio Di Franco, Fabrizio Galeazzi and Valentina Vassallo (eds) Authenticity and Cultural Heritage in the Age of 3D Digital Reproductions, 1-9, Cambridge: McDonald Institute. https://doi.org/https://doi.org/10.17863/CAM.27029

Drucker, J. (2011) 'Humanities Approaches to Graphical Display', Digital Humanities Quarterly, 5 (1).

Dudley, S. (2010) Museum Materialities: Objects, Engagements, Interpretations, London: Routledge.

(2012) Narrating Objects, Collecting Stories: Essays in Honour of Professor Susan M. Pearce, Abingdon: Routledge.

Edwards, E. and Hart, J. (2004) Photographs Objects Histories. On the Materiality of Images, London: Routledge.

Edwards, E. and Morton, C. (2015) Photographs, Museums, Collections: Between Art and Information, Bloomsbury Publishing.

Engel, D. and Phillips, J. (2019) 'Applying Conservation Ethics to the Examination and Treatment of Software- and Computer-based Art', Journal of the American Institute for Conservation, 58 (3) 180-95. https://doi.org/10.1080/01971360.2019.1598124 
Foti, P. (2018) Collecting and Exhibiting Computer-Based Technology: Expert Curation at the Museums of the Smithsonian Institution, London: Routledge.

Fuchs, C. (2014) Digital Labour and Karl Marx, London: Routledge.

Garcia Raso, D. (2017) Yacimiento píxel: Los videojuegos como cultura material, Madrid: YAS Arqueologia.

Geismar, H. (2016) 'Instant Archives?', in Larissa Hjorth, Heather Horst, Anne Galloway and Genevieve Bell (eds) The Routledge Companion to Digital Ethnography, 35769, London: Routledge.

(2018) Museum Object Lessons for the Digital Age, London: UCL Press.

Gell, A. (1998) Art and Agency: An Anthropological Theory, Oxford, New York: Clarendon Press.

Giaccardi, E. and Plate, L. (2016). 'How Memory Comes to Matter: From Social Media to the Internet of Things', in László Muntean, Liedeke Plate and Anneke Smelik (eds) Materializing Memory in Art and Popular Culture, 65-88, New York and Abingdon: Taylor \& Francis.

Gosden, C. and Larson, F. (2007) Knowing Things: Exploring the Collections at the Pitt Rivers Museum, 1884-1945, Oxford, New York: Oxford University Press.

Hartig, K., Uimonen, P., Boogh, E., Jensen, B. and Wallenius, A. (2020) Connect to Collect: Approaches to Collecting Social Digital Photography in Museums and Archives, Stockholm: Nordiska museets förlag. http://urn.kb.se/ resolve?urn=urn:nbn:se:nordiskamuseet:diva-2140

Hassard, J. and Law, J. (1999) Actor Network Theory and After, Oxford: Blackwell.

Hicks, D. (2010) 'The Material-Cultural Turn: Event and Effect', in Dan Hicks and Mary C. Beaudry (eds) The Oxford Handbook of Material Culture Studies, 25-98, Oxford: Oxford University Press.

Hill, K. (2012) Museums and Biographies: Stories, Objects, Identities, Woodbridge: Boydell.

Hine, C. (2000) Virtual Ethnography, London: SAGE.

Holtorf, C. (2002) 'Notes on the Life History of a Pot Sherd', Journal of Material Culture, 7 49-71. https://doi.org/10.1177/1359183502007001305

Horst, H.A. and Miller, D. (eds) (2012) Digital Anthropology, London: Bloomsbury.

Huhtamo, E. and Parikka, J. (2011) Media Archaeology: Approaches, Applications, and Implications, Berkeley: University of California Press.

Janes, R.R. and Sandell, R. (2019) Museum Activism, Abingdon: Routledge. https://library. oapen.org/handle/20.500.12657/46427

Jeffrey, S. (2015) Challenging Heritage Visualisation: Beauty, Aura and Democratisation, Open Archaeology 1 144-52. https://doi.org/10.1515/opar-2015-0008

Jones, S., Jeffrey, S., Maxwell, M., Hale, A., and Jones, C. (2018) '3D Heritage Visualisation and the Negotiation of Authenticity: The ACCORD Project', International Journal of Heritage Studies, 24 (4) 333-53. https://doi.org/10.1080/135 $\underline{27258.2017 .1378905}$ 
Kirschenbaum, M.G. (2008) Mechanisms: New Media and the Forensic Imagination, Cambridge, MA: MIT Press.

Kopytoff, I. (1986) 'The Cultural Biography of Things: Commoditization as Process', in Arjun Appadurai (ed) The Social Life of Things: Commodities in Cultural Perspective, 64-91, Cambridge: Cambridge University Press.

Kowalchuk, S. (2018) '“Deep-Fried” and Denaturalized: Critiquing Memetic MetaOntologies', AolR Selected Papers of Internet Research, 2018: $19^{\text {th }}$ Annual Conference of the Association of Internet Researchers, Montreal, Canada. https:// doi.org/10.5210/spir.v2018i0.10490

Kozinets, R.V. (2010) Netnography: Doing Ethnographic Research Online, London: SAGE.

Latour, B. (2005) Reassembling the Social: An Introduction to Actor-Network-Theory, Oxford: Clarendon Press.

Latour, B. and Lowe, A. (2010) 'The Migration of the Aura - or How to Explore the Original through Its Facsimiles', in Thomas Bartscherer and Roderick Coover (eds) Switching Codes: Thinking through Digital Technology in the Humanities and the Arts, 275-97, Chicago: University of Chicago Press. http://www.bruno-latour.fr/ node/151

Lievrouw, L.A. and Livingstone, S.M. (2006) Handbook of New Media: Social Shaping and Consequences of ICTs, London: SAGE.

Mairesse, F., Desvallées, A. and Deloche, B. (2010) Key Concepts of Museology, Paris: Armand Colin.

Manovich, L. (2001) The Language of New Media, Cambridge, MA and London: MIT Press.

(2009) 'The Practice of Everyday (Media) Life: From Mass Consumption to Mass Cultural Production?', Critical Inquiry, 35 (2) 319-31. https://doi.org/10.1086/596645

Meehan, N. (2020) 'Digital Museum Objects and Memory: Postdigital Materiality, Aura and Value', Curator. https://doi.org/10.1111/cura.12361

Milligan, I. (2017) 'Welcome to the Web: The Online Community of GeoCities during the Early Years of the World Wide Web', in Niels Brügger and Ralph Schroeder (eds) The Web as History: Using Web Archives to Understand the Past and the Present, 137-58, London: UCL Press. https://doi.org/10.14324/111.9781911307563

Moshenska, G. (2014) 'The Archaeology of (Flash) Memory', Post-Medieval Archaeology, 48 (1) 255-59. https://doi.org/https://doi.org/10.1179/0079423614Z.00000000055

Murthy, D. (2011) 'Emergent Digital Ethnography Methods for Social Research', in Sharlene Nagy Hesse-Biber (ed) The Handbook of Emergent Technologies in Social Research, 158-79, Oxford: Oxford University Press.

Parikka, J. (2012) What is Media Archaeology? Cambridge: Polity Press.

Paul, C. (2015) Digital Art, $3^{\text {rd }}$ edn., London and New York: Thames and Hudson.

(2017) 'From Archives to Collections', in Oliver Grau, Wendy Coones and Viola Rühse (eds) Museum and Archive on the Move: Changing Cultural Institutions in the Digital Era, 184-97, Berlin, Boston: De Gruyter. 
Pearce, S.M. (1992) Museums, Objects and Collections: A Cultural Study, Leicester: Leicester University Press.

(1994) Interpreting Objects and Collections, London: Routledge.

Pink, S., Horst, H., Postill, J., Hjorth, L., Lewis, T. and Tacchi, J. (2016) Digital Ethnography: Principles and Practice, Los Angeles: SAGE.

Pomian, K. (1990) Collectors and Curiosities: Paris and Venice 1500-1800, Cambridge: Polity Press.

Reinhard, A. (2018) Archaeogaming: An Introduction to Archaeology in and of Video Games, New York: Berghahn Books.

Star, S.L. and Griesemer, J.R. (1989) 'Institutional Ecology, "Translations" and Boundary Objects: Amateurs and Professionals in Berkeley's Museum of Vertebrate Zoology, 1907-39', Social Studies of Science, 19 387-420. https://doi. org/10.1177/030631289019003001

Tifentale, A. and Manovich, L. (2015) 'Selfiecity: Exploring Photography and Selffashioning in Social Media', in David M. Berry and Michael Dieter (eds) Postdigital Aesthetics: Art, Computation and Design, 109-22, Basingstoke: Palgrave Macmillan UK.

Vann, P., Bruns, A. and Harrington, S. (2019) 'Transmedia Social Platforms: Livestreaming and Transmedia Sports', in Matthew Freeman and Renira Rampazzo Gambarato (eds) The Routledge Companion to Transmedia Studies, 107-115, New York and Abingdon: Routledge.

Waters, D. and Garrett, J. (1996) Preserving Digital Information: Report of the Task Force on Archiving of Digital Information commissioned by The Commission on Preservation and Access and The Research Libraries Group. https://archive.org/ details/PreservingDigitallnformationTaskForceReport1996

\section{Notes}

1 UNESCO, 'Charter on the Preservation of Digital Heritage', 2003. https://www.unesco.at/ fileadmin/Redaktion/Publikationen/Publikations-Dokumente/UNESCO-Charter on the Preservation of Digital Heritage.pdf, accessed 20 May 2021.

2 Juhee Park and Anouska Samms, 'The Materiality of the Immaterial: Collecting Digital Objects at the Victoria and Albert Museum', Museums and the Web 2019. https://mw19. mwconf.org/paper/the-materiality-of-the-immaterial-collecting-digital-objects-at-thevictoria-and-albert-museum/, accessed 12 June 2021.

3 Chiara Zuanni, 'Museum Digital Projects during COVID-19: from Lockdown Connections to Digital Transformation?', Museums and the Web 2021. https://mw21.museweb.net/ paper/museum-digital-projects-during-covid-19-from-lockdown-connections-to-digitaltransformation/, accessed 12 June 2021.

4 AA.VV., 'The London Charter for the Computer-based Visualisation of Cultural Heritage', 2009. https://www.londoncharter.org, accessed 20 May 2021.

5 AA.VV., 'Principles of Seville. International Principles of Virtual Archaeology', 2011. http:// sevilleprinciples.com, accessed 20 May 2021. 
6 Bergis Jules, Ed Summers and Vernon Mitchell, Jr., 'Documenting The Now White Paper: Ethical Considerations for Archiving Social Media Content Generated by Contemporary Social Movements: Challenges: Opportunities, and Recommendations', Documenting the Now April 2018. https://www.docnow.io/docs/docnow-whitepaper-2018.pdf, accessed 20 May 2021.

\section{Author}

Chiara Zuanni

chiara.zuanni@uni-graz.at

ORCID iD: https://orcid.org/0000-0003-4027-0278

URL: http://bit.ly/uni-profile

University of Graz

Austria

\section{Bio Statement}

Chiara Zuanni is an assistant professor in Digital Humanities at the Centre for Information Modelling - Austrian Centre for Digital Humanities at the University of Graz. Her research focuses on the construction and mediation of knowledge in museums, the impact of digital media on the heritage sector and its audiences, digital data practices in museums, and born digital collecting. 